\title{
ADUBAÇÃO FOSFATADA E COMPACTAÇÃO DO SOLO: SISTEMA RADICULAR DA SOJA E DO MILHO E ATRIBUTOS FÍSICOS DO SOLO
}

\author{
Franciele Caroline de Assis Valadão(1), Oscarlina Lúcia dos Santos Weber(2), Daniel Dias \\ Valadão Júnior(1)*, Alex Scapinelli(1), Filipe Rafaeli Deina(1) e Aloísio Bianchini(2)
}

\begin{abstract}
(1) Instituto Federal de Mato Grosso, Campo Novo do Parecis, Mato Grosso, Brasil.
(2) Universidade Federal de Mato Grosso, Faculdade de Agronomia, Medicina Veterinária e Zootecnia, Cuiabá, Mato Grosso, Brasil.

* Autor correspondente.

E-mail: daniel.valadao@cnp.ifmt.edu.br
\end{abstract}

\begin{abstract}
RESUMO
Associadas aos benefícios no solo da semeadura direta, podem ocorrer a formação de gradiente vertical de fertilidade e a de uma camada compactada provocada pelo intenso tráfego de máquinas agrícolas, podendo modificar o crescimento radicular das culturas. $O$ objetivo deste trabalho foi avaliar as doses e formas de aplicação da adubação fosfatada e a compactação do solo pelo tráfego de máquinas nos atributos físicos e no sistema radicular da soja e do milho nas condições da Chapada dos Parecis, MT. O estudo foi realizado em Latossolo Vermelho-Amarelo distrófico argiloso em delineamento em blocos casualizados, no esquema fatorial $2 \times 4 \times 4 \mathrm{e}$ três repetições, sendo duas formas de adubação fosfatada (a lanço e no sulco), quatro doses de $\mathrm{P}_{2} \mathrm{O}_{5}\left(0,50,100\right.$ e $\left.150 \mathrm{~kg} \mathrm{ha}^{-1}\right)$ e quatro níveis de compactação (PT0, PT2, PT4 e PT8 - semeadura direta com compactação induzida por tráfego de trator em zero, duas, quatro e oito passadas, respectivamente). $O$ tráfego de máquinas ocasionou compactação do solo em semeadura direta, aumentando a densidade do solo (Ds) e resistência do solo à penetração (RSP) e reduzindo a macroporosidade e porosidade total, sem efeito da adubação fosfatada. A resposta das espécies à forma de adubação fosfatada foi diferenciada, não apresentando influência no crescimento radicular da soja. No milho, quando fornecida a lanço proporcionou maior área de raízes na camada de 0,00-0,05 m; e, quando no sulco, foram observadas entre as camadas menores diferenças na área radicular. Nas camadas de 0,05-0,10 e 0,10-0,20 m, a RSP de 1,48 e 1,84 MPa (Us = 0,28 $\left.\mathrm{m}^{3} \mathrm{~m}^{-3}\right)$ e Ds de 1,32 e 1,35 kg dm-3 , respectivamente, proporcionaram redução de 19 e $27 \%$ no diâmetro médio das raízes do milho e aumento de 110 e 49 \% no diâmetro das raízes da soja.
\end{abstract}

Palavras-chave: área radicular, Glycine max, Zea mays, resistência do solo à penetração. 


\title{
ABSTRACT: PHOSPHORUS FERTILIZATION AND SOIL COMPACTION: SOYBEAN AND MAIZE ROOT SYSTEM AND SOIL PHYSICAL PROPERTIES
}

\begin{abstract}
Associated with the benefits of the no-till system for the soil, there may be the formation of a vertical gradient of fertility and a compacted layer caused by heavy farm machine traffic, which may modify the root growth of crops. The aim of this study was to evaluate the effect of rates and forms of phosphate fertilizer application and soil compaction by machine traffic on the physical properties and root system of soybeans and maize. The study was conducted in Campo Novo do Parecis, MT, Brazil, in a clayey Latossolo Vermelho-Amarelo distrófico (Oxisol) in a randomized block experimental design with three replications. A $2 \times 4 \times 4$ factorial arrangement was used, consisting of two forms of phosphate fertilization (broadcast

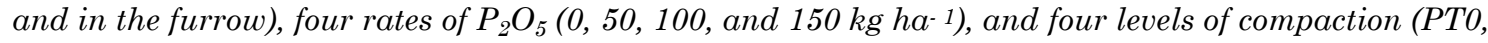
PT2, PT4, and PT8 - no-tillage with compaction induced by tractor traffic at zero, two, four, and eight passes, respectively). Machine traffic causes soil compaction in no-tillage, increasing soil bulk density (Bd) and soil resistance to penetration (SRP) and reducing macroporosity and total porosity, without effect from $P$ fertilization. The response of the species to the form of $P$ fertilization was differentiated. There was no significant influence on root growth in soybean, but in maize, broadcast fertilization provided for greater root area in the root zone in the 0.00-0.05 $\mathrm{m}$ layer, and fertilization in the furrow led to smaller differences in root area between the layer. The SRP values of 1.48 and $1.84 \mathrm{MPa}\left(\mathrm{Us}=0.28 \mathrm{~m}^{3} \mathrm{~m}^{-3}\right)$ and $B d$ values of 1.32 and $1.35 \mathrm{~kg} \mathrm{dm}-3$ in the 0.05-0.10 and 0.10-0.20 m layers, respectively, resulted in a reduction of 19 and $27 \%$ in the average diameter of corn roots, and an increase of 110 and $49 \%$ in the diameter of soybean roots.
\end{abstract}

Keywords: root area, Glycine max, Zea mays, soil resistance to penetration.

\section{INTRODUÇÃO}

A oferta de máquinas e a de defensivos agrícolas viabilizaram o cultivo das culturas em semeadura direta. Juntamente com os benefícios proporcionados e comprovados por essa técnica, como melhoria dos teores de matéria orgânica, ciclagem de nutrientes e conservação do solo, há a formação de gradiente vertical de fertilidade, principalmente de $\mathrm{P}$ (Santos et al., 2008). Há também o surgimento de uma camada compactada provocada pelo tráfego de máquinas agrícolas associado ao revolvimento do solo apenas na linha de semeadura (Freddi et al., 2007; Bergamin et al., 2010).

Nessa camada compactada, há alteração no balanço entre macro e microporos e na porosidade total do solo, influenciando o espaço destinado ao crescimento radicular e área explorada de solo pelas raízes (Beutler e Centurion, 2004; Bergamin et al., 2010). Isso pode influenciar a difusão do $\mathrm{P}$ até o sistema radicular, já que entre os fatores considerados na sua estimativa estão a área radicular, a distância do elemento até a unidade de absorção e o gradiente de concentração do elemento (Malavolta, 2006). Assim, tanto o manejo da adubação como as condições físicas do solo podem influenciar a quantidade de $\mathrm{P}$ absorvida pelas plantas e, consequentemente, a produtividade de grãos. Santos et al. (2005) verificaram que maiores doses de $\mathrm{P}_{2} \mathrm{O}_{5}$ foram necessárias nos solos mais compactados para manter as características produtivas do milho semelhante àquelas obtidas nos tratamentos não compactados.
A resposta das culturas à compactação parece ser dependente da disponibilidade hídrica no solo (Beutler e Centurion, 2003), da espécie cultivada (Secco et al., 2009) e do cultivar utilizado (Cardoso et al., 2006). Em leguminosas, diferentes resultados foram obtidos quanto à modificação do sistema radicular e da produtividade de grãos. Guimarães et al. (2002) observaram aumento do diâmetro e redução da densidade radicular de feijão quando a densidade do solo (Ds) passou de 1,0 para $1,6 \mathrm{~kg} \mathrm{dm}^{-3}$. Leonel et al. (2007) notaram a mesma resposta no amendoim quando a resistência passou de 1,8 para 4,0 $\mathrm{MPa}$ (umidade na capacidade de campo). Porém, o aumento de resistência do solo de 0,26 para $1,98 \mathrm{MPa}$ em solo com umidade de $90 \%$ da capacidade de campo não foi impeditivo para o desenvolvimento do sistema radicular da soja quando estudado por Foloni et al. (2006).

Em gramíneas, a compactação parece interferir com maior intensidade as características das plantas. Bergamin et al. (2010), em Latossolo Vermelho argiloso, observaram, além de alterações nos atributos físicos do solo, que a compactação reduziu o comprimento, a superfície e o diâmetro médio de raízes de milho até $0,20 \mathrm{~m}$ de profundidade, quando a Ds passou de 1,12 para $1,23 \mathrm{~kg} \mathrm{dm}^{-3} \mathrm{na}$ camada de $0,00-0,05 \mathrm{~m}$ e de 1,28 para $1,37 \mathrm{~kg} \mathrm{dm}^{-3}$, na de 0,05-0,10 $\mathrm{m}$ de profundidade. Secco et al. (2009) demonstraram reduções significativas na produtividade do milho e trigo em dois Latossolos sob compactação, mas não verificaram efeito na soja.

Os problemas criados pela compactação podem ser agravados pelo manejo da adubação fosfatada, 
pois, quando fornecida a lanço em áreas de semeadura direta, pode aumentar a concentração de $\mathrm{P}$ na superfície em relação à subsuperfície (Santos et al., 2008). Pelo maior contato entre adubo e solo, podem exigir maiores doses de fertilizantes para se obter a mesma eficiência que a adubação no sulco de semeadura (Prado et al., 2001). A maior concentração do nutriente em superfície pode influenciar o crescimento radicular e produtividade das culturas, principalmente em condições de deficiência hídrica e solo compactado.

Poucos trabalhos na literatura têm demonstrado o efeito do manejo da adubação fosfatada em áreas de semeadura direta, sobretudo em solos com presença de camada compactada. Assim, buscou-se neste trabalho avaliar as doses e formas de aplicação da adubação fosfatada e a compactação do solo pelo tráfego de máquinas nos atributos físicos e no sistema radicular da soja e do milho nas condições da Chapada dos Parecis, MT.

\section{MATERIAL E MÉTODOS}

O estudo foi realizado no campo experimental do Instituto Federal de Mato Grosso, Campo Novo do Parecis, MT, de novembro de 2012 a julho de 2013 , com o cultivo de soja na primeira safra e milho na segunda. A Instituição está localizada na Chapada dos Parecis a $13^{\circ} 40^{\prime} 31^{\prime \prime}$ sul e $57^{\circ} 53^{\prime} 31^{\prime \prime}$ oeste com $572 \mathrm{~m}$ de altitude. $\mathrm{O}$ solo foi classificado como Latossolo Vermelho-Amarelo distrófico típico (Embrapa, 2006). As características do solo na camada de 0,00-0,20 m são: $\mathrm{pH}\left(\mathrm{CaCl}_{2}\right): 5,4$; $\mathrm{P}$ e K (Mehlich-1):16,9 e $29 \mathrm{mg} \mathrm{dm}{ }^{-3} ; \mathrm{Ca}^{2+}, \mathrm{Mg}^{2+}$ e $\mathrm{Al}^{3+}\left(\mathrm{KCl} 1 \mathrm{~mol} \mathrm{~L}^{-1}\right): 3,1 ; 1,1$ e $0,0 \mathrm{cmol}_{\mathrm{c}} \mathrm{dm}^{-3}$; $\mathrm{H}+\mathrm{Al}$ (Acetato de cálcio $\mathrm{pH} 7,0$ ): $3,1 \mathrm{cmol}_{\mathrm{c}} \mathrm{dm}^{-3}$; MO (Walkley e Black): 21,2 $\mathrm{g} \mathrm{dm}^{-3}$; e areia, silte e argila (Embrapa, 1997): 360, 134 e $506 \mathrm{~g} \mathrm{~kg}^{-1}$.
O clima da região segundo a classificação de Köppen é Aw, cujos dados de temperatura e precipitação pluvial no período de realização do experimento encontram-se na figura 1 . A área do experimento foi cultivada nos últimos três anos em sucessão entre soja e milho em semeadura direta, sendo nos cinco anos anteriores deixada em pousio com vegetação espontânea e apresentava a média de produção de palhada seca de $1,5 \mathrm{Mg}$ ha-1 $\left( \pm 0,23 \mathrm{Mg}^{-1}\right)^{-1}$.

O delineamento experimental foi em blocos casualizados em esquema fatorial $2 \times 4 \times 4$ com três repetições, sendo duas formas de adubação fosfatada (no sulco de semeadura e a lanço), quatro doses de $\mathrm{P}_{2} \mathrm{O}_{5}\left(0,50,100\right.$ e $\left.150 \mathrm{~kg} \mathrm{ha}^{-1}\right)$ e quatro níveis de compactação (PT0, PT2, PT4 e PT8 - semeadura direta com compactação induzida por tráfego de trator em zero, duas, quatro e oito passadas, respectivamente), o que totalizou 32 tratamentos e 96 parcelas.

Como fonte de $\mathrm{P}$, em ambas as culturas, foi utilizado o monoamônio fosfatado (MAP - $58 \%$ $\mathrm{P}_{2} \mathrm{O}_{5}$ solúvel), e a indução da compactação foi realizada após as primeiras chuvas, quando o solo possuía conteúdo de água determinado conforme Embrapa (1997) na camada de 0,00-0,20 m próximo à capacidade de campo $\left(0,30 \mathrm{~m}^{3} \mathrm{~m}^{-3}\right)$.

Foi utilizado trator agrícola MF $292(105 \mathrm{cv})$, com rodado de pneus diagonais, bitola traseira de $1,7 \mathrm{~m}$ e massa total de $5,0 \mathrm{Mg}$ com pressão de inflação de $95 \mathrm{kPa}$ nos pneus dianteiros (14.9-24 R1) e $110 \mathrm{kPa}$ nos traseiros (19.4-34 R1), sendo $41 \%$ da massa distribuídas no eixo dianteiro e $59 \%$ no eixo traseiro. Para garantir os níveis de compactação, foi adicionado a esse trator mais $1,0 \mathrm{Mg}$ de massa por meio de duas vigas de concreto acopladas na parte dianteira e duas na parte traseira, o que correspondeu $6,0 \mathrm{Mg}$ de massa sobre o solo por passada de trator. Durante o tráfego do trator, foi utilizada a segunda marcha reduzida com uma rotação de $1.600 \mathrm{rpm}$ e velocidade de $5 \mathrm{~km} \mathrm{~h}^{-1}$.

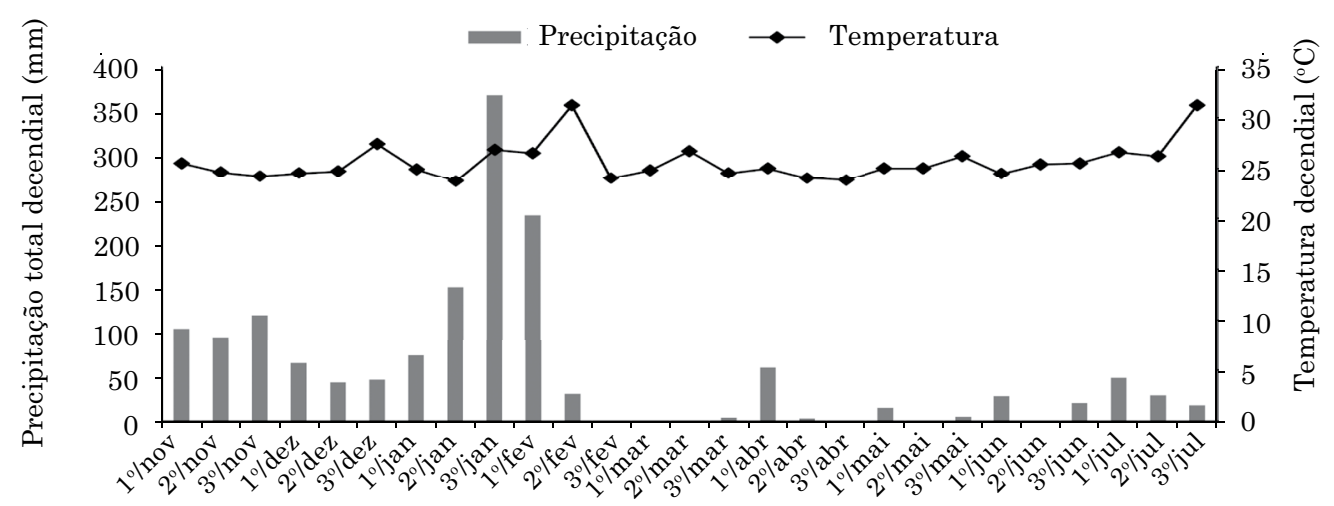

Figura 1. Precipitação pluvial total e temperatura média do ar em cada decêndio na área experimental, no período de novembro de 2012 a julho de 2013. 
Esse trator trafegou toda a superfície da parcela, de forma que os pneus comprimiram áreas paralelas entre si (Figura 2). O número de vezes trafegado variou conforme o tratamento; o tráfego foi sobreposto ao anterior, de forma que toda área de cada parcela foi trafegada com número igual de vezes.

A unidade experimental tinha $3,4 \mathrm{~m}$ de comprimento e $3,15 \mathrm{~m}$ de largura, perfazendo área total de $10,71 \mathrm{~m}^{2}$. Foi utilizado espaçamento entrelinhas de $0,45 \mathrm{~m}$. Como área útil, foram consideradas as três linhas centrais com 1,0 m linear cada no centro da parcela.

Para garantir que as plantas atingissem toda a área compactada, tanto a semeadura da soja como a do milho ocorreram no sentido contrário do tráfego do trator (Figura 2).

A semeadura da soja (cultivar 98Y12 - ciclo precoce) foi efetuada manualmente e ocorreu no dia 2 de novembro de 2012 com densidade de 16 sementes por metro linear. Foi feita inoculação das sementes com Bradyrhizobium japonicum estirpes SEMIA 5079 e $5080(5 \times 109$ bactérias por $\mathrm{mL}$ do produto) e utilizada como adubação de base $100 \mathrm{~kg} \mathrm{ha}^{-1}$ de $\mathrm{K}_{2} \mathrm{O}$, sendo a fonte o cloreto de potássio $\left(60 \% \mathrm{~K}_{2} \mathrm{O}\right)$ aplicado no sulco de semeadura.

Para neutralizar o efeito do $\mathrm{N}$ fornecido em maior quantidade com o aumento das doses de $\mathrm{MAP}$, a diferença de $\mathrm{N}$ entre as doses do adubo fosfatado foi fornecida na forma de ureia $(45 \%$ de N), correspondendo a 28,$44 ; 18,97 ; 9,48$; e $0,00 \mathrm{~kg} \mathrm{ha}^{-1}$ de $\mathrm{N}$ para as respectivas doses de $\mathrm{P}_{2} \mathrm{O}_{5}$. A adubação nitrogenada seguiu a forma de adubação fosfatada no sulco ou a lanço, conforme o tratamento.

A semeadura do milho (híbrido 30K75 - ciclo precoce) ocorreu em 16 de fevereiro de 2013, depois da colheita da soja, também de forma manual. Foi feita adubação de base com $40 \mathrm{~kg} \mathrm{ha}^{-1}$ de $\mathrm{N}$, na forma de ureia, e $100 \mathrm{~kg} \mathrm{ha}^{-1}$ de $\mathrm{K}$, como cloreto de potássio; e mantiveram-se as doses e formas de aplicação de $\mathrm{P}_{2} \mathrm{O}_{5}$ conforme os tratamentos da soja. A adubação de base de $\mathrm{N}$ também foi corrigida conforme as doses da adubação fosfatada com MAP resultando na aplicação de 40; 30,52; 21,03; e 11,56 $\mathrm{kg} \mathrm{ha}^{-1}$ de $\mathrm{N}$, respectivamente para as doses de $0,50,100$ e $150 \mathrm{~kg}$ ha-1 de $\mathrm{P}_{2} \mathrm{O}_{5}$. No estádio V7, foi realizada adubação de cobertura com ureia na dose de $80 \mathrm{~kg} \mathrm{ha}^{-1}$ de $\mathrm{N}$.

Quando as culturas entraram no estádio R2, foi avaliado o sistema radicular pelo método da trincheira e feita análise do perfil por imagem (Jorge e Silva, 2010). Em cada parcela, de maneira aleatória, foi aberta uma trincheira transversal a uma linha de cultivo, onde a parede vertical da trincheira ficou a $0,05 \mathrm{~m}$ da planta, expondo a raiz dessa planta por meio de lavagem com água. Após a exposição das raízes em seção transversal à linha de cultivo e próxima ao eixo da planta, o perfil foi dividido em quadrículas de $0,05 \mathrm{~m}$, com auxílio de uma malha de $0,40 \times 0,30 \mathrm{~m}$ colocada em pleno contato com o solo (Figura 3). Efetuou-se, então, a fotografia do perfil com câmera digital (12 megapixels). Posteriormente, as raízes foram estimadas nas camadas de 0,0-0,05; $0,05-0,10 ; 0,10-0,15 ; 0,15-0,20 ;$ e $0,20-0,30 \mathrm{~m}$, quanto à área $\left(\mathrm{m}^{2} \mathrm{~m}^{-2}\right)$ e ao diâmetro médio $(\mathrm{m})$ por meio da técnica de limiarização (thresholding) com o programa Safira (Jorge e Silva, 2010).

Para as determinações de densidade (Ds, kg $\mathrm{dm}^{-3}$ ) e espaço poroso do solo, foram coletadas amostras indeformadas em cilindros metálicos com 0,05 m de diâmetro e 0,041 m de altura, nas mesmas profundidades em que se realizou a análise de raízes. As amostras foram retiradas nas entrelinhas d a cultura do milho. Em cada parcela e profundidade, foram coletadas aleatoriamente três subamostras, sendo utilizado o valor médio como representativo da parcela.

Após o preparo das amostras, essas foram saturadas por capilaridade para obtenção da macroporosidade (Mac, $\mathrm{m}^{3} \mathrm{~m}^{-3}$ ), microporosidade (Mic, $\mathrm{m}^{3} \mathrm{~m}^{-3}$ ) e porosidade total $\left(\mathrm{Pt}, \mathrm{m}^{3} \mathrm{~m}^{-3}\right)$ pela mesa de tensão calibrada a 0,006 $\mathrm{MPa}$, conforme descrito em Embrapa (1997).
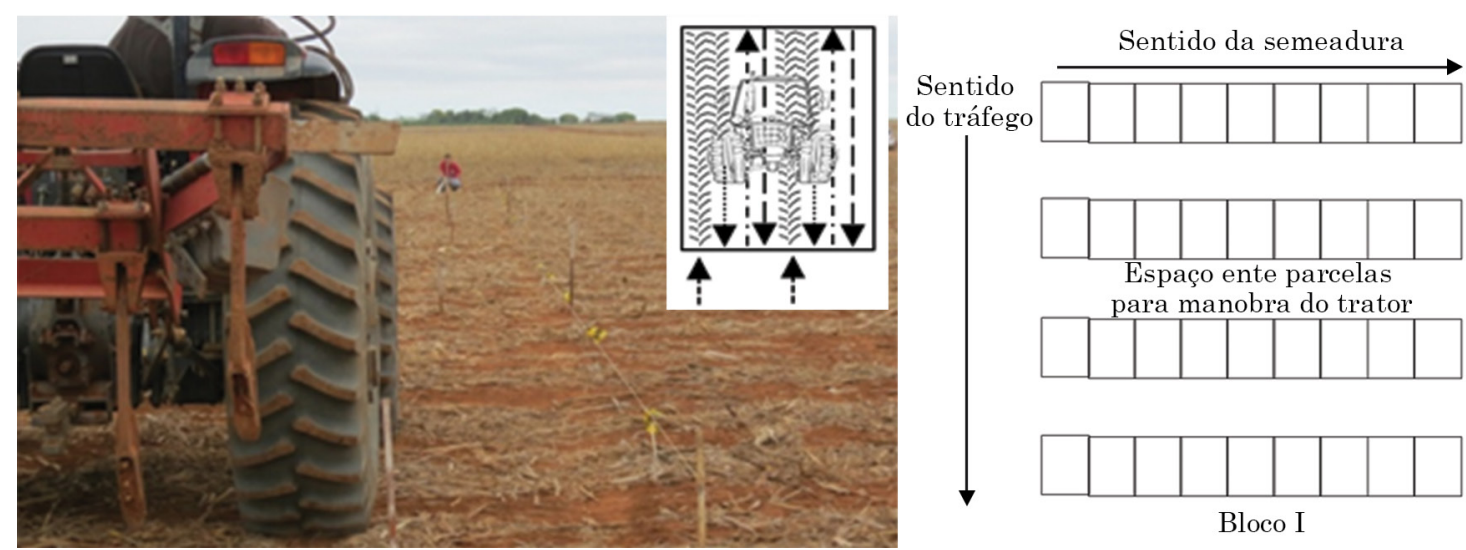

Figura 2. Croqui de um bloco da área experimental ilustrando, em detalhe, o tráfego do trator. 


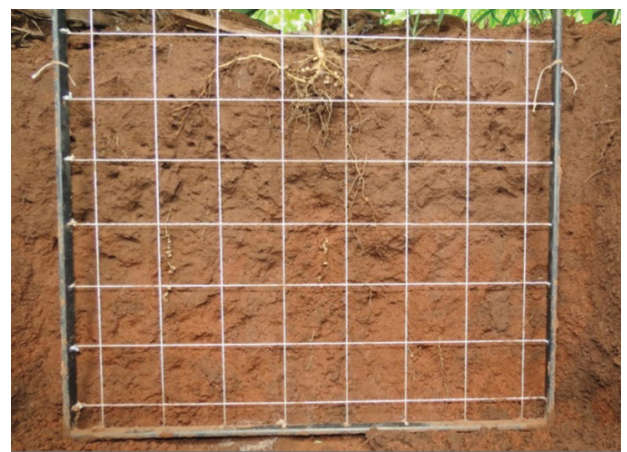

Figura 3. Distribuição das raízes de soja em perfil de $0,40 \times 0,30 \mathrm{~m}$ e, em detalhe, quadrículas de $0,05 \times 0,05 \mathrm{~m}$ utilizadas na medição do sistema radicular por meio da técnica de limiarização.

Foi feita também no campo a medida de resistência do solo à penetração (RSP), utilizando penetrógrafo eletrônico automático portátil com velocidade de penetração constante de $30 \mathrm{~mm} \mathrm{~s}^{-1} \mathrm{e}$ cone de 129,28 $\mathrm{mm}^{2}$ de área de base desenvolvido por Bianchini et al. (2002). Nesse momento, foi retirada uma amostra de solo em cada camada de avaliação para determinar o conteúdo de água.

Os dados foram submetidos à análise de variância, e quando $\mathrm{F}$ significativo $(\mathrm{p}<0,05)$ foi aplicado o teste de Tukey $(p<0,05)$ para a compactação e as formas de adubação, e análise de regressão para as doses de $\mathrm{P}_{2} \mathrm{O}_{5}$, respeitando-se as respectivas interações. As análises foram feitas no programa estatístico Minitab 16.

\section{RESULTADOS E DISCUSSÃO}

Os atributos físicos do solo foram alterados a partir de PT2, mas não foram influenciados pela adubação fosfatada (Quadro 1). A energia aplicada nas áreas trafegadas promoveu a reorganização das partículas e gerou arranjo mais compacto, havendo aumento da densidade do solo (Ds) e resistência do solo à penetração (RSP) e redução da macroporosidade (Mac) e porosidade total (Pt); porém, sem efeito sobre a umidade do solo (Us) e a microporosidade (Mic) (Quadro 1). Isso evidenciou que a carga aplicada por duas passadas de $6,0 \mathrm{Mg}$ do trator sobre o solo foi suficiente para provocar alterações nesse.

A Ds foi alterada até $0,30 \mathrm{~m}$ de profundidade e a RSP até $0,20 \mathrm{~m}$; porém, para ambas as variáveis, o maior efeito ocorreu na camada de $0,00-0,10 \mathrm{~m}$, onde houve maior diferença entre PT0 e os sistemas que foram trafegados. Assim, na semeadura direta, o tráfego de máquinas e implementos pode provocar maior compactação nas camadas mais superficiais (até $0,10 \mathrm{~m}$ ) em relação às subsuperficiais (abaixo de
0,10 m) (Freddi et al., 2007; Bergamin et al., 2010; Valicheski et al., 2012). Todavia, conforme foi verificado nos tratamentos PT4 e PT8, alguma modificação em subsuperfície pode ocorrer sob tráfego muito intenso e umidade favorável à compactação, pois houve alteração da Ds e RSP nas camadas abaixo de $0,10 \mathrm{~m}$.

Freddi et al. (2007) e Bergamin et al. (2010) também constataram alterações nos atributos físicos do solo pelo tráfego de trator em áreas de semeadura direta. Entretanto, as modificações ocorreram apenas na camada superficial $(0,00-0,10 \mathrm{~m})$. Nesse experimento, a umidade favorável à compactação (umidade na capacidade de campo), a baixa cobertura vegetal, as características inerentes ao próprio solo e ao trator podem ter condicionado a compactação em camadas abaixo de $0,10 \mathrm{~m}$, quando comparado ao tratamento que não recebeu compactação adicional. Isso pode ocorrer pelo solo argiloso na umidade na capacidade de campo apresentar alta plasticidade, característica que faz o solo deformar-se lentamente em razão da carga aplicada, não havendo reversão quando essa é removida; dessa forma, o solo fica mais suscetível à compactação em maiores profundidades (Machado et al., 2005).

Também, um fator que corrobora a compactação em profundidade é a pressão de inflação dos pneus do trator utilizado. Machado et al. (2005) estudaram três pressões de inflação dos pneus traseiros do trator com massa total de aproximadamente $6,0 \mathrm{Mg}$, sendo 55,125 e $165 \mathrm{kPa}$, permanecendo constante a pressão dos pneus dianteiro com $95 \mathrm{kPa}$. Os autores encontraram que as maiores pressões de inflação dos pneus (125 e $165 \mathrm{kPa}$ ) provocaram menores áreas de contato entre o solo e o pneu; por consequência, maior pressão desse sobre o solo, fato que provocou compactação até $0,30 \mathrm{~m}$ de profundidade com valores de RSP maiores que 2,0 MPa. Neste trabalho, a pressão de inflação dos pneus traseiros foi de $110 \mathrm{kPa}$ e provocou compactação semelhante àquela obtida pelos autores citados.

$\mathrm{Na}$ camada superficial $(0,00-0,10 \mathrm{~m})$ do tratamento PT2, houve redução de 26 e $7 \%$ dos valores de Mac e $\mathrm{Pt}$, respectivamente, em relação a PT0. Para a mesma camada, em PT8, houve redução de 58 e $16 \%$ dos valores de Mac e $\mathrm{Pt}$, o que correspondeu, em relação a PT0, a mudança de Ds média de 1,10 para $1,31 \mathrm{~kg} \mathrm{dm}^{-3}$. Nas demais camadas, o efeito do tráfego do trator sobre o arranjo de poros do solo foi menor, porém permaneceu até $0,30 \mathrm{~m}$ para o tratamento PT8. Nesse sistema, a Mac $\left(0,08 \mathrm{~m}^{3} \mathrm{~m}^{-3}\right)$ ficou abaixo do valor considerado crítico para mínima aeração do solo e desenvolvimento das raízes $\left(0,10 \mathrm{~m}^{3} \mathrm{~m}^{-3}\right)$ (Pagliai et al., 2003).

Valores semelhantes de redução da Mac foram encontrados por Bergamin et al. (2010) em Latossolo Vermelho argiloso, utilizando trator com pneus e massa semelhantes aos deste trabalho. Os autores observaram redução 
Quadro 1. Atributos físicos nas diferentes camadas do solo em razão do número de passadas de trator (PTn) avaliados durante o cultivo do milho

\begin{tabular}{|c|c|c|c|c|c|c|}
\hline Camada & PT0 & PT2 & PT4 & PT8 & DMS & $\mathrm{CV}$ \\
\hline \multirow[t]{2}{*}{$\mathrm{m}$} & & & & & & $\%$ \\
\hline & \multicolumn{6}{|c|}{ Densidade do solo $\left(\mathrm{kg} \mathrm{dm}^{-3}\right)$} \\
\hline $0,00-0,05$ & $1,09 \mathrm{C}$ & $1,21 \mathrm{~B}$ & $1,26 \mathrm{AB}$ & $1,30 \mathrm{~A}$ & 0,07 & 5,43 \\
\hline $0,05-0,10$ & $1,12 \mathrm{C}$ & $1,22 \mathrm{~B}$ & $1,29 \mathrm{~A}$ & $1,32 \mathrm{~A}$ & 0,07 & 5,16 \\
\hline $0,10-0,15$ & $1,18 \mathrm{~B}$ & $1,23 \mathrm{~B}$ & $1,31 \mathrm{~A}$ & $1,34 \mathrm{~A}$ & 0,06 & 4,45 \\
\hline $0,15-0,20$ & $1,20 \mathrm{C}$ & $1,28 \mathrm{~B}$ & $1,30 \mathrm{AB}$ & $1,35 \mathrm{~A}$ & 0,05 & 4,20 \\
\hline \multirow[t]{2}{*}{$0,20-0,30$} & $1,24 \mathrm{~B}$ & $1,26 \mathrm{AB}$ & $1,27 \mathrm{AB}$ & $1,30 \mathrm{~A}$ & 0,05 & 3,42 \\
\hline & \multicolumn{6}{|c|}{ Resistência do solo à penetração (MPa) } \\
\hline $0,00-0,05$ & $0,35 \mathrm{~B}$ & $0,72 \mathrm{~A}$ & $0,74 \mathrm{~A}$ & $0,80 \mathrm{~A}$ & 0,30 & 27,59 \\
\hline $0,05-0,10$ & $1,07 \mathrm{~B}$ & $1,30 \mathrm{AB}$ & $1,44 \mathrm{~A}$ & $1,48 \mathrm{~A}$ & 0,26 & 19,55 \\
\hline $0,10-0,15$ & $1,32 \mathrm{C}$ & $1,40 \mathrm{BC}$ & $1,66 \mathrm{AB}$ & $1,68 \mathrm{~A}$ & 0,27 & 16,88 \\
\hline $0,15-0,20$ & $1,74 \mathrm{~B}$ & $1,78 \mathrm{AB}$ & $1,99 \mathrm{~A}$ & $2,00 \mathrm{~A}$ & 0,24 & 12,59 \\
\hline \multirow[t]{2}{*}{$0,20-0,30$} & $1,85 \mathrm{~A}$ & $1,85 \mathrm{~A}$ & $1,88 \mathrm{~A}$ & $1,90 \mathrm{~A}$ & 0,24 & 11,31 \\
\hline & \multicolumn{6}{|c|}{ Umidade do solo $\left(\mathrm{m}^{3} \mathrm{~m}^{-3}\right)$} \\
\hline $0,00-0,05$ & $0,29 \mathrm{~A}$ & $0,29 \mathrm{~A}$ & $0,30 \mathrm{~A}$ & $0,30 \mathrm{~A}$ & 0,02 & 8,19 \\
\hline $0,05-0,10$ & $0,29 \mathrm{~A}$ & $0,29 \mathrm{~A}$ & $0,29 \mathrm{~A}$ & $0,28 \mathrm{~A}$ & 0,02 & 5,96 \\
\hline $0,10-0,15$ & $0,28 \mathrm{~A}$ & $0,28 \mathrm{~A}$ & $0,27 \mathrm{~A}$ & $0,28 \mathrm{~A}$ & 0,02 & 5,46 \\
\hline $0,15-0,20$ & $0,27 \mathrm{~A}$ & $0,28 \mathrm{~A}$ & $0,28 \mathrm{~A}$ & $0,28 \mathrm{~A}$ & 0,02 & 5,24 \\
\hline \multirow[t]{2}{*}{$0,20-0,30$} & $0,28 \mathrm{~A}$ & $0,28 \mathrm{~A}$ & $0,28 \mathrm{~A}$ & $0,28 \mathrm{~A}$ & 0,02 & 5,50 \\
\hline & \multicolumn{6}{|c|}{ Macroporosidade $\left(\mathrm{m}^{3} \mathrm{~m}^{-3}\right)$} \\
\hline $0,00-0,05$ & $0,19 \mathrm{~A}$ & $0,14 \mathrm{~B}$ & $0,10 \mathrm{C}$ & $0,08 \mathrm{C}$ & 0,03 & 24,53 \\
\hline $0,05-0,10$ & $0,20 \mathrm{~A}$ & $0,13 \mathrm{~B}$ & $0,12 \mathrm{~B}$ & $0,08 \mathrm{C}$ & 0,03 & 20,70 \\
\hline $0,10-0,15$ & $0,16 \mathrm{~A}$ & $0,13 \mathrm{~B}$ & $0,12 \mathrm{~B}$ & $0,08 \mathrm{C}$ & 0,02 & 17,17 \\
\hline $0,15-0,20$ & $0,15 \mathrm{~A}$ & $0,12 \mathrm{~B}$ & $0,11 \mathrm{~B}$ & $0,08 \mathrm{C}$ & 0,02 & 18,58 \\
\hline \multirow[t]{2}{*}{$0,20-0,30$} & $0,14 \mathrm{~A}$ & $0,12 \mathrm{~A}$ & $0,12 \mathrm{~A}$ & $0,08 \mathrm{~B}$ & 0,02 & 18,10 \\
\hline & \multicolumn{6}{|c|}{ Microporosidade $\left(\mathrm{m}^{3} \mathrm{~m}^{-3}\right)$} \\
\hline $0,00-0,05$ & $0,38 \mathrm{~A}$ & $0,39 \mathrm{~A}$ & $0,39 \mathrm{~A}$ & $0,40 \mathrm{~A}$ & 0,03 & 6,81 \\
\hline $0,05-0,10$ & $0,36 \mathrm{~A}$ & $0,38 \mathrm{~A}$ & $0,38 \mathrm{~A}$ & $0,39 \mathrm{~A}$ & 0,03 & 5,98 \\
\hline $0,10-0,15$ & $0,38 \mathrm{~A}$ & $0,38 \mathrm{~A}$ & $0,38 \mathrm{~A}$ & $0,38 \mathrm{~A}$ & 0,02 & 3,10 \\
\hline $0,15-0,20$ & $0,36 \mathrm{~A}$ & $0,36 \mathrm{~A}$ & $0,37 \mathrm{~A}$ & $0,37 \mathrm{~A}$ & 0,02 & 4,41 \\
\hline \multirow[t]{2}{*}{$0,20-0,30$} & $0,37 \mathrm{~A}$ & $0,37 \mathrm{~A}$ & $0,37 \mathrm{~A}$ & $0,38 \mathrm{~A}$ & 0,05 & 3,88 \\
\hline & \multicolumn{6}{|c|}{ Porosidade total $\left(\mathrm{m}^{3} \mathrm{~m}^{-3}\right)$} \\
\hline $0,00-0,05$ & $0,57 \mathrm{~A}$ & $0,53 \mathrm{~B}$ & $0,49 \mathrm{C}$ & $0,48 \mathrm{C}$ & 0,03 & 5,33 \\
\hline $0,05-0,10$ & $0,56 \mathrm{~A}$ & $0,51 \mathrm{~B}$ & $0,51 \mathrm{~B}$ & $0,47 \mathrm{C}$ & 0,03 & 5,09 \\
\hline $0,10-0,15$ & $0,54 \mathrm{~A}$ & $0,51 \mathrm{AB}$ & $0,50 \mathrm{~B}$ & $0,46 \mathrm{C}$ & 0,03 & 4,26 \\
\hline $0,15-0,20$ & $0,52 \mathrm{~A}$ & $0,48 \mathrm{~B}$ & $0,48 \mathrm{~B}$ & $0,46 \mathrm{~B}$ & 0,03 & 4,58 \\
\hline $0,20-0,30$ & $0,52 \mathrm{~A}$ & $0,49 \mathrm{AB}$ & $0,48 \mathrm{BC}$ & $0,45 \mathrm{C}$ & 0,03 & 5,37 \\
\hline
\end{tabular}

Médias seguidas por letras iguais não diferem entre si pelo teste Tukey $(\mathrm{p}>0,05)$. Letras maiúsculas comparam compactação dentro de cada camada, ou seja, na linha. PT0, PT2, PT4, PT8: zero, duas, quatro e oito passadas de trator, respectivamente. DMS: diferença mínima significativa. CV: coeficiente de variação.

da Mac de 26 e $44 \%$ na camada de 0,00-0,05 e 0,05-0,10 m, respectivamente, quando compararam o tratamento não trafegado (valores médios nessas camadas de $\mathrm{Ds}=1,22 \mathrm{~kg} \mathrm{dm}^{-3}, \mathrm{RSP}=0,49 \mathrm{MPa} \mathrm{e}$ $\mathrm{Us}_{\mathrm{s}}=0,40 \mathrm{~m}^{3} \mathrm{~m}^{-3}$ ), com o tratamento que recebeu quatro passadas de trator ( $\mathrm{Ds}=1,29 \mathrm{~kg} \mathrm{dm}^{-3}$, $\mathrm{RSP}=0,72 \mathrm{MPa}$ e $\left.\mathrm{Us}_{\mathrm{s}}=0,72 \mathrm{~m}^{3} \mathrm{~m}^{-3}\right)$. Valicheski et al.
(2012), também trabalhando com trator semelhante ao deste estudo em solo argiloso, verificaram redução de $0,05 \mathrm{~m}^{3} \mathrm{~m}^{-3}$ na $\mathrm{Pt}$ no tratamento com duas passadas ( $\mathrm{Ds}=1,32 \mathrm{~kg} \mathrm{dm}^{-3}, \mathrm{RSP}=1,43 \mathrm{MPa} \mathrm{e}$ $\left.\mathrm{Us}_{\mathrm{s}}=0,25 \mathrm{~m}^{3} \mathrm{~m}^{-3}\right)$, em relação ao tratamento que não recebeu compactação adicional ( $\mathrm{Ds}_{\mathrm{s}}=1,21 \mathrm{~kg} \mathrm{dm}^{-3}$, $\mathrm{RSP}=0,29 \mathrm{MPa}$ e Us $\left.=0,25 \mathrm{~m}^{3} \mathrm{~m}^{-3}\right)$. 
Apesar de alteração nos valores de Mac e Pt, não foi observado efeito sobre a Mic (Quadro 1). Isso ocorreu pelos poros de menor diâmetro apresentar maior resistência à deformação em relação aos macroporos e à maior capacidade de suporte de carga conforme observado por Bergamin et al. (2010), que também não encontraram alterações na Mic sob tráfego adicional em semeadura direta.

Apesar de solos compactados poderem ter maiores valores de umidade volumétrica (Beutler and Centurion, 2003; Bergamin et al., 2010), não foi observado efeito sobre esse atributo neste trabalho. Isso provavelmente tenha ocorrido pela coleta da RSP (momento de coleta da amostra para umidade) ter sido feita após incidência de chuva (aproximadamente $24 \mathrm{~h}$ ) na área experimental. Isso pode ter feito com que as amostras tenham sido coletadas com a água ainda em processo de drenagem, não representando, portanto, água armazenada, sendo menos influenciada pela Ds. Pode ter contribuído ainda para a não diferença, a ausência de efeito do tráfego sobre a microporosidade, responsável pela retenção de água no solo.

Em resumo, a Ds e RSP não foram significativamente alteradas a partir de quatro passadas de trator; no entanto, a porosidade foi alterada até oito passadas. Isso indica que pequenas alterações, mesmo que não significativas na Ds e RSP, são suficientes para reduzir significativamente o espaço poroso do solo.

Quanto ao sistema radicular da soja e do milho, foram observadas respostas e interações diferenciadas para cada cultura. Para área e diâmetro de raiz da soja, houve efeito da compactação (Quadro 2) sem interação com a adubação fosfatada. Para essas características no milho, houve interação entre compactação e forma de adubação fosfatada (Quadro 3).

A ausência de resposta no sistema radicular da soja às formas de adubação provavelmente tenha ocorrido pela primeira adubação a lanço não ter provocado diferenças no teor de $\mathrm{P}$ em profundidade suficiente para promover alguma resposta no sistema radicular dessa cultura.

O tráfego de trator alterou a área do sistema radicular da soja, bem como a distribuição no perfil do solo (Figura 4). Em PT8 (Ds $=1,30 \mathrm{~kg} \mathrm{dm}^{-3} \mathrm{e}$ RSP de 0,80 $\mathrm{MPa}$ ), houve redução de $23 \%$ da área de raiz na camada de 0,00-0,05 $\mathrm{m}$ em comparação com PT0 (Ds = 1,09 kg dm ${ }^{-3}$ e RSP = 0,35 MPa), e não foi possível detectar a área radicular a partir de $0,15 \mathrm{~m}$ de profundidade (Quadro 2). Nas camadas de $0,05-0,10 ; 0,10-0,15 ; 0,15-0,20$; e $0,20-0,30 \mathrm{~m}$, houve redução de 41, 49, 50 e $89 \%$ da área de raiz a partir de PT2 (Quadro 2). Em PT0, 45 \% das raízes se concentravam até $0,05 \mathrm{~m}$, enquanto em PT2, PT4 e PT8, 59, 65 e $75 \%$ das raízes se concentravam até essa profundidade (Quadro 2).

A compactação aumentou o diâmetro das raízes de soja, sendo $122,59 \%$ maior no sistema PT8, em relação a PT0 (Quadro 2). Pela análise do perfil do solo no momento da abertura da trincheira, foi possível observar deformação do sistema radicular com característico engrossamento das raízes secundárias a ponto de não ser possível a identificação da raiz principal, alterando de forma significativa o diâmetro médio (Figura 4).

Segundo Torres e Saraiva (1999), o impedimento mecânico diminui a taxa de elongação radicular por causa da redução da divisão celular meristemática, tornando as raízes menos pontiagudas e,

Quadro 2. Área e diâmetro médio do sistema radicular da soja nas diferentes camadas do solo em razão do número de passadas de trator (PTn)

\begin{tabular}{|c|c|c|c|c|c|c|}
\hline Camada & PT0 & PT2 & PT4 & PT8 & DMS & $\mathrm{CV}$ \\
\hline \multirow[t]{2}{*}{$\mathrm{m}$} & & & & & & $\%$ \\
\hline & \multicolumn{6}{|c|}{ Área $\left(\mathrm{m}^{2} \mathrm{~m}^{-2}\right)$} \\
\hline $0,00-0,05$ & $0,237 \mathrm{~A}$ & $0,217 \mathrm{AB}$ & $0,212 \mathrm{AB}$ & $0,183 \mathrm{~B}$ & 0,053 & 40,12 \\
\hline $0,05-0,10$ & $0,165 \mathrm{~A}$ & $0,098 \mathrm{~B}$ & $0,073 \mathrm{BC}$ & $0,050 \mathrm{C}$ & 0,041 & 30,55 \\
\hline $0,10-0,15$ & $0,082 \mathrm{~A}$ & $0,040 \mathrm{~B}$ & $0,031 \mathrm{BC}$ & $0,011 \mathrm{C}$ & 0,029 & 21,53 \\
\hline $0,15-0,20$ & $0,023 \mathrm{~A}$ & 0,011 B & $0,008 \mathrm{BC}$ & $0,000 \mathrm{C}$ & 0,011 & 28,99 \\
\hline \multirow[t]{2}{*}{$0,20-0,30$} & $0,016 \mathrm{~A}$ & $0,002 \mathrm{~B}$ & $0,000 \mathrm{~B}$ & $0,000 \mathrm{~B}$ & 0,012 & 47,06 \\
\hline & \multicolumn{6}{|c|}{ Diâmetro $\left(\mathrm{m} \times 10^{-3}\right)$} \\
\hline $0,00-0,05$ & $0,481 \mathrm{C}$ & $0,532 \mathrm{BC}$ & 0,633 B & $1,071 \mathrm{~A}$ & 0,121 & 12,19 \\
\hline $0,05-0,10$ & $0,441 \mathrm{~B}$ & $0,574 \mathrm{~B}$ & $0,711 \mathrm{~A}$ & $0,810 \mathrm{~A}$ & 0,136 & 22,07 \\
\hline $0,10-0,15$ & $0,350 \mathrm{~B}$ & $0,461 \mathrm{AB}$ & $0,534 \mathrm{~A}$ & $0,521 \mathrm{~A}$ & 0,154 & 15,75 \\
\hline $0,15-0,20$ & $0,222 \mathrm{~A}$ & $0,200 \mathrm{AB}$ & $0,150 \mathrm{~B}$ & - & 0,060 & 34,99 \\
\hline $0,20-0,30$ & $0,151 \mathrm{~A}$ & $0,151 \mathrm{~A}$ & - & - & 0,089 & 46,01 \\
\hline
\end{tabular}

Médias seguidas por mesma letra não diferem entre si pelo teste Tukey $(p>0,05)$. Letras maiúsculas comparam compactação dentro de cada camada. PT0, PT2, PT4, PT8: zero, duas, quatro e oito passadas de trator, respectivamente. DMS: diferença mínima significativa. CV: coeficiente de variação. 
Quadro 3. Área e diâmetro médio do sistema radicular do milho nas diferentes camadas de solo em razão da forma da adubação fosfatada e do número de passadas de trator (PTn)

\begin{tabular}{|c|c|c|c|c|c|c|c|c|}
\hline Camada & Forma & PT0 & PT2 & PT4 & PT8 & DMS $^{1}$ & DMS $^{2}$ & $\mathrm{CV}$ \\
\hline \multirow[t]{2}{*}{$\mathrm{m}$} & & & & & & & & $\%$ \\
\hline & & \multicolumn{7}{|c|}{ Área $\left(\mathrm{m}^{2} \mathrm{~m}^{-2}\right)$} \\
\hline \multirow[t]{2}{*}{$0,00-0,05$} & Lanço & $0,426 \mathrm{Ba}$ & $0,430 \mathrm{Ba}$ & $0,593 \mathrm{ABa}$ & $0,652 \mathrm{Aa}$ & \multirow{2}{*}{0,196} & & \multirow{2}{*}{38,67} \\
\hline & Sulco & $0,447 \mathrm{Aa}$ & 0,433 Aa & $0,370 \mathrm{Bb}$ & $0,388 \mathrm{Bb}$ & & 0,147 & \\
\hline \multirow[t]{2}{*}{$0,05-0,10$} & Lanço & 0,391 Aa & $0,299 \mathrm{Bb}$ & $0,192 \mathrm{Cb}$ & $0,192 \mathrm{Cb}$ & \multirow{2}{*}{0,089} & & \multirow{2}{*}{40,12} \\
\hline & Sulco & $0,402 \mathrm{Aa}$ & $0,397 \mathrm{ABa}$ & $0,312 \mathrm{BCa}$ & $0,293 \mathrm{Ca}$ & & 0,083 & \\
\hline \multirow[t]{2}{*}{$0,10-0,15$} & Lanço & $0,299 \mathrm{Aa}$ & 0,199 Bb & $0,099 \mathrm{Ca}$ & $0,093 \mathrm{Ca}$ & \multirow{2}{*}{0,050} & & \multirow{2}{*}{35,99} \\
\hline & Sulco & 0,307 Aa & $0,297 \mathrm{Aa}$ & $0,134 \mathrm{Ba}$ & $0,105 \mathrm{Ba}$ & & 0,069 & \\
\hline \multirow[t]{2}{*}{$0,15-0,20$} & Lanço & $0,197 \mathrm{Ab}$ & $0,141 \mathrm{Bb}$ & $0,046 \mathrm{Cb}$ & $0,002 \mathrm{Db}$ & \multirow{2}{*}{0,035} & & \multirow{2}{*}{32,51} \\
\hline & Sulco & $0,297 \mathrm{Aa}$ & $0,173 \mathrm{Ba}$ & 0,101 Ca & $0,092 \mathrm{Ca}$ & & 0,026 & \\
\hline \multirow[t]{3}{*}{$0,20-0,30$} & Lanço & $0,091 \mathrm{Ab}$ & $0,077 \mathrm{Aa}$ & $0,028 \mathrm{Bb}$ & $0,001 \mathrm{Bb}$ & \multirow{2}{*}{0,027} & & \multirow{2}{*}{29,19} \\
\hline & Sulco & $0,127 \mathrm{Aa}$ & 0,081 Ba & $0,057 \mathrm{Ba}$ & 0,069 Ba & & 0,021 & \\
\hline & & \multicolumn{7}{|c|}{ Diâmetro $\left(\mathrm{m} \times 10^{-3}\right)$} \\
\hline $0,00-0,05$ & - & $0,911 \mathrm{~A}$ & 0,891 A & $0,770 \mathrm{~B}$ & $0,741 \mathrm{~B}$ & 0,091 & & 15,16 \\
\hline $0,05-0,10$ & - & $0,892 \mathrm{~A}$ & $0,882 \mathrm{~A}$ & $0,770 \mathrm{~B}$ & $0,764 \mathrm{~B}$ & 0,111 & & 23,30 \\
\hline $0,10-0,15$ & - & $0,894 \mathrm{~A}$ & $0,883 \mathrm{~A}$ & $0,782 \mathrm{~B}$ & $0,652 \mathrm{C}$ & 0,094 & & 14,89 \\
\hline $0,15-0,20$ & - & $0,802 \mathrm{~A}$ & $0,794 \mathrm{~A}$ & 0,691 B & $0,491 \mathrm{C}$ & 0,082 & & 10,11 \\
\hline $0,20-0,30$ & - & $0,750 \mathrm{~A}$ & $0,530 \mathrm{~B}$ & $0,370 \mathrm{~B}$ & $0,263 \mathrm{C}$ & 0,214 & & 40,57 \\
\hline
\end{tabular}

Letras iguais não diferem entre si pelo teste Tukey $(\mathrm{p}>0,05)$. Dentro de cada camada, letras maiúsculas comparam compactação em cada forma de adubação (DMS ${ }^{1}$ ); e letras minúsculas comparam forma de adubação em cada nível de compactação (DMS²). PT0, PT2, PT4, PT8: zero, duas, quatro e oito passadas de trator, respectivamente. DMS: diferença mínima significativa. CV: coeficiente de variação.

consequentemente, provocando maior engrossamento das raízes. Guimarães et al. (2002), em Latossolo Vermelho com $49 \%$ de argila, observaram aumento da espessura das raízes de feijão a partir da Ds de $1,2 \mathrm{~kg} \mathrm{dm}^{-3}$. Leonel et al. (2007), em Latossolo Vermelho com $32 \%$ de argila, verificaram aumento linear do diâmetro de raiz de amendoim quando a RSP variou de 0,83 a 3,57 MPa na camada de 0,00-0,05 m de profundidade com umidade de $0,16 \mathrm{~m}^{3} \mathrm{~m}^{-3}$.

Todavia, Beutler e Centurion (2004), em Latossolo Vermelho de textura média, encontraram aumento da densidade radicular, do diâmetro e da massa de matéria seca das raízes localizadas na camada de 0,00-0,05 m com o aumento da compactação do solo até RSP de 2,44 $\mathrm{MPa}$ (Us = capacidade de campo). A partir desse valor, esses autores acharam redução de diâmetro pela maior emissão de raízes secundárias finas. Os valores de RSP encontrados neste trabalho ficaram abaixo dos encontrados por aqueles autores, indicando que, possivelmente, a partir de um limite de compactação haja emissão de raízes finas e redução do diâmetro médio, limite esse não encontrado.

Diferentemente da soja, a área e distribuição de raízes de milho no perfil do solo foram influenciadas pela interação entre compactação e forma de adubação (Figura 5). Isso pode ter ocorrido pela diferença natural na arquitetura do sistema radicular e também porque o cultivo de milho foi realizado com a segunda adubação a lanço, aumentado o gradiente vertical de fertilidade. Na adubação a lanço, a área ocupada por raízes de milho na camada de 0,00-0,05 $\mathrm{m}$ aumentou com o número de passadas do trator, reduzindo significativamente em profundidade (Figura 5). Nessa forma de adubação, em PT0, $30 \%$ do sistema radicular encontravam-se na camada de 0,00-0,05 m (Quadro 3). Em PT8, esse valor passou para $69 \%$, limitando-se $92 \%$ do sistema radicular até $0,15 \mathrm{~m}$ (Quadro 3).

Quando a forma de adubação foi no sulco, independentemente da camada, houve redução da área radicular com o aumento do número de passadas do trator (Quadro 3). Em PT0, 28 \% das raízes limitavam-se na camada de 0,00-0,05 m, enquanto em PT8 esse valor foi de $41 \%$ (Quadro 3). Nessa forma de adubação, verificou-se presença de raízes até $0,30 \mathrm{~m}$ de profundidade, mesmo nos sistemas mais compactados (Figura 5). De forma geral, a adubação a lanço proporcionou maior área de raiz de milho em superfície $(0,00-0,05 \mathrm{~m})$; e a adubação no sulco, em subsuperfície (camadas abaixo de $0,05 \mathrm{~m}$ ). Isso provavelmente tenha ocorrido por ter havido maior concentração de $\mathrm{P}$ na camada superficial pela adubação a lanço sem incorporação, conforme destacado por Santos et al. (2008).

Barreto e Fernandes (2002) encontraram melhor distribuição do sistema radicular do milho quando utilizaram adubação a lanço. Contudo, esses autores 

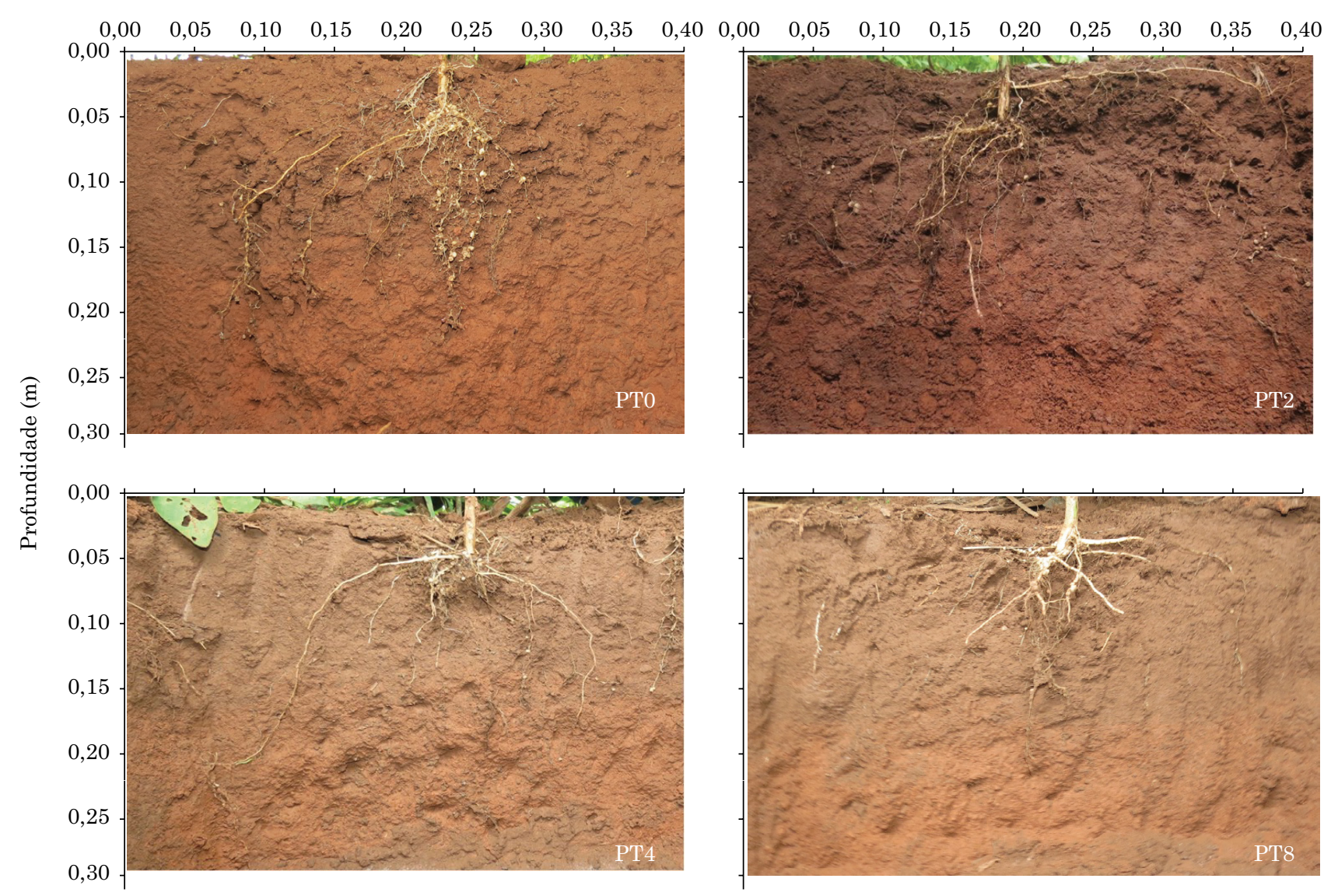

Figura 4. Distribuição das raízes da soja até $0,30 \mathrm{~m}$ de profundidade do solo, em decorrência de zero (PT0), duas (PT2), quatro (PT4) e oito (PT8) passadas de trator.

trabalharam com adubação a lanço incorporada até $0,20 \mathrm{~m}$ em um Argissolo de textura arenosa, que apresentou baixa retenção de P. Neste estudo, a segunda aplicação seguida a lanço sob manejo de semeadura direta em solo de textura argilosa provavelmente provocou aumento do gradiente vertical de P. Esse fato aliado à maior Ds e RSP e menor Mac e Pt (Quadro 1) comprometeu o desenvolvimento radicular.

Ao contrário da soja, o diâmetro das raízes do milho foi reduzido com o aumento da compactação, sem interação com os demais fatores (Quadro 3). Bergamin et al. (2010), em Latossolo Vermelho argiloso, verificaram que a compactação do solo influenciou negativamente o comprimento, a superfície e o diâmetro médio radicular do milho, até $0,20 \mathrm{~m}$ de profundidade. A redução no diâmetro de raízes do milho pode estar associada à emissão de raízes laterais de menor diâmetro, sendo uma adaptação às condições restritivas impostas pela compactação, para que as raízes possam penetrar no espaço poroso do solo também de menor diâmetro, a fim de obter água e nutrientes para o seu desenvolvimento (Clark et al., 2003; Bergamin et al., 2010). Nesse caso, as raízes do milho, pela arquitetura fasciculada, possuem maior capacidade de penetrar as fissuras provocadas em solos compactados do que as de soja.

Pode-se inferir, portanto, que a resposta à compactação depende da cultura, uma vez que houve aumento do diâmetro para a cultura da soja e redução para o milho, para a faixa de compactação utilizada neste trabalho. Assim, possivelmente as RSP de $1,48 \mathrm{MPa}\left(\mathrm{Us}_{\mathrm{s}}=0,28 \mathrm{~m}^{3} \mathrm{~m}^{-3}\right)$ e Ds de $1,32 \mathrm{~kg} \mathrm{dm}^{-3}$, na camada de 0,05-0,10 m, e RSP de 1,84 MPa $\left(\mathrm{Us}_{\mathrm{s}}=0,28 \mathrm{~m}^{3} \mathrm{~m}^{-3}\right)$ e Ds de $1,35 \mathrm{~kg} \mathrm{dm}^{-3}$, na camada de $0,10-0,20 \mathrm{~m}$, foram suficientes para aumentar a produção de raízes finas e reduzir o diâmetro médio das raízes do milho, mas não as da soja.

As doses de $\mathrm{P}_{2} \mathrm{O}_{5}$ proporcionaram respostas semelhantes no sistema radicular da soja e do milho (Figura 6).

Com o aumento das doses de $\mathrm{P}_{2} \mathrm{O}_{5}$, houve aumento linear na área radicular da soja na camada de 0,00-0,15 m, independentemente do nível de compactação e forma de adubação (Figura 6a). As doses aumentaram de forma quadrática o diâmetro das raízes de soja na camada de 0,00-0,05 m; não houve efeito de 0,05-0,15 m, mas de efeito quadrático de 0,15-0,20 m e linear de 0,20-0,30 m 

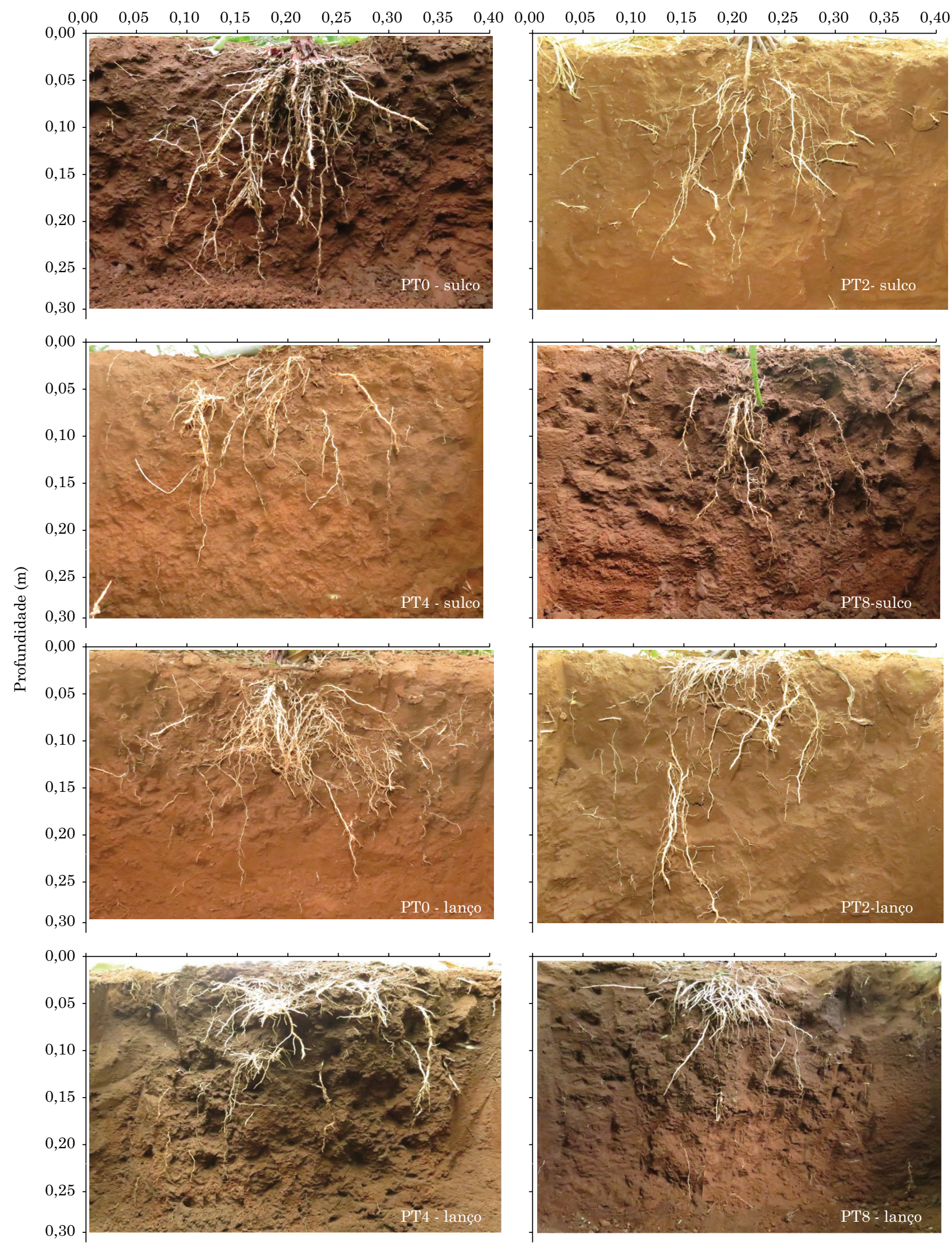

Figura 5. Distribuição das raízes do milho até $30 \mathrm{~cm}$ de profundidade do solo em decorrência de: zero (PT0), duas (PT2), quatro (PT4) e oito (PT8) passadas de trator. 


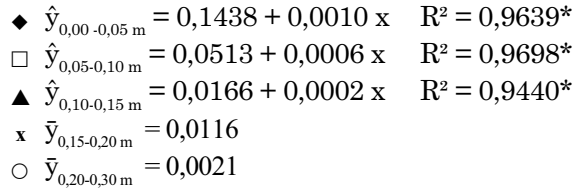

(a)
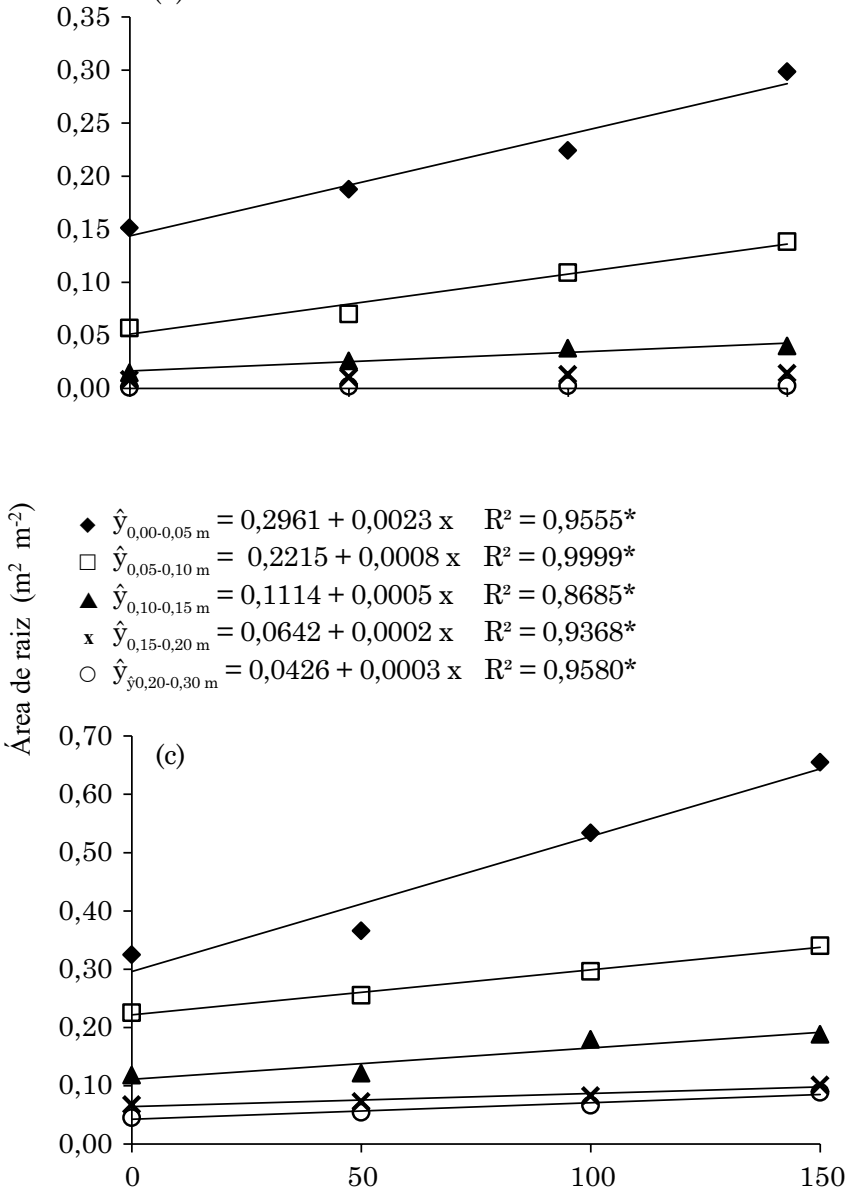

- $\hat{\mathrm{y}}_{0,00-0,05 \mathrm{~m}}=0,4185+0,0058 \mathrm{x}-0,0000^{2} \mathrm{x}^{2} \quad \mathrm{R}^{2}=0,9995^{*}$

$\square \overline{\mathrm{y}}_{0,05-0,10 \mathrm{~m}}=0,4574$

A $\bar{y}_{0,10-0,15 \mathrm{~m}}=0,4225$

x $\hat{\mathrm{y}}_{0,15-0,2 \mathrm{~m}}=0,3230+0,0030 \mathrm{x}-0,000001 \mathrm{x}^{2} \mathrm{R}^{2}=0,9913^{*}$

$\circ \hat{\mathrm{y}}_{0,20-0,30 \mathrm{~m}}=0,046+0,0011 \mathrm{x} \quad \mathrm{R}^{2}=0,9561^{*}$

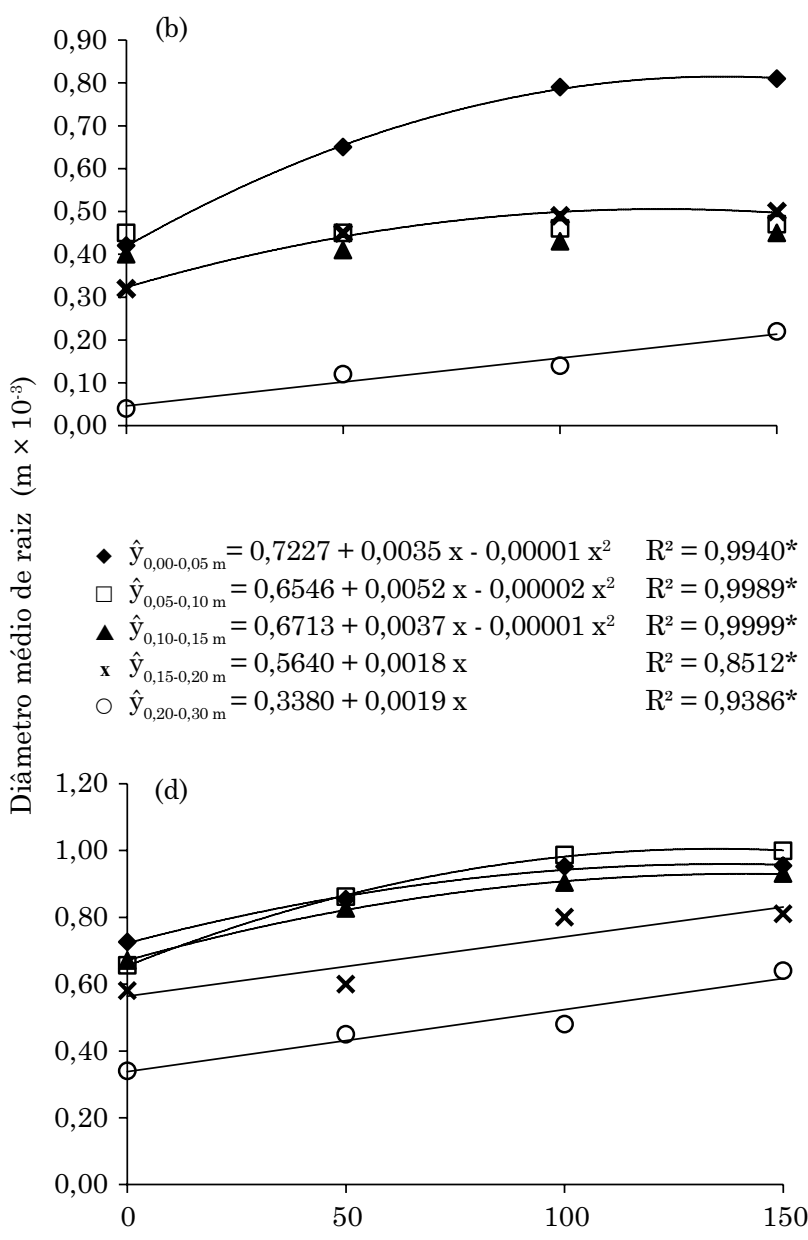

Dose de $\mathrm{P}_{2} \mathrm{O}_{5}\left(\mathrm{~kg} \mathrm{ha}^{-1}\right)$

Figura 6. Área e diâmetro de raiz da soja (a, b) e do milho (c, d) em diferentes camadas de solo em função das doses de $\mathbf{P}$ na adubação. * significativo pelo teste $F(p<0,05)$.

(Figura 6b). Em relação ao milho, as doses de $\mathrm{P}_{2} \mathrm{O}_{5}$ proporcionaram aumento linear sobre a área radicular até $0,30 \mathrm{~m}$ de profundidade (Figura $6 \mathrm{c}$ ); e quanto ao diâmetro, houve efeito quadrático até $0,15 \mathrm{~m}$; entre 0,15 e $0,30 \mathrm{~m}$ o efeito foi linear positivo (Figura 6d).

Crusciol et al. (2005), com a cultura do arroz, verificaram maior formação de raízes e aumento do diâmetro radicular com o aumento das doses de P. Segundo esses autores, a redução do diâmetro das raízes sob baixa disponibilidade de $\mathrm{P}$ seria adequação da planta de forma que essa apresentasse geometria radicular mais favorável à absorção de $\mathrm{P}_{2} \mathrm{O}_{5}$. Dessa forma, aliada à redução do diâmetro das raízes do milho e ao engrossamento das raízes de soja em solos compactados, é demonstrada a capacidade de cada cultura em sobreviver em condições extremas de estresse nutricional e hídrico.

Ao analisar a baixa área radicular das culturas nas camadas mais profundas do solo em condições de compactação, as maiores doses de $\mathrm{P}_{2} \mathrm{O}_{5}$ atuam como condicionador do crescimento radicular em subsuperfície, uma vez, que houve aumento da área radicular com a elevação das doses de $\mathrm{P}_{2} \mathrm{O}_{5}$. Esses resultados corroboram os de Santos et al. (2005), ao verificarem que o $\mathrm{P}$ aplicado funcionou como fator de aliviamento da compactação do solo, resultando em maior produção para o mesmo grau de compactação, tanto em Latossolos de textura argilosa e média quanto em Neossolo Quartzarênico. 
Nas duas safras, da soja e do milho, houve baixa disponibilidade hídrica durante o ciclo, com irregularidade de precipitação pluvial, ficando a média abaixo do precipitado de anos anteriores (Figura 1). Provavelmente, esse fato fez com que houvesse também oscilações de RSP durante o ciclo, uma vez que esse atributo é dependente das condições hídricas do solo (Beutler e Centurion, 2003), o que pode ter intensificado o efeito da compactação e adubação sobre o crescimento das raízes de ambas as culturas. De tal modo, pode-se inferir que o tráfego intenso em áreas de semeadura direta, sem adequada cobertura vegetal, pode causar compactação do solo e, conjugado com a ausência de correção da fertilidade em subsuperfície acentuado pela adubação a lanço sem incorporação, pode modificar o sistema radicular das culturas e ser intensificado sob condições de estresse hídrico, podendo haver reduções significativas de produtividade.

Também, um fator que contribui para a manifestação dos resultados negativos da compactação e adubação a lanço deve estar associado aos cultivares utilizados de ciclo precoce, que, sob o efeito de estresse no início do desenvolvimento, não teve tempo de se recuperar interferindo drasticamente no sistema radicular. Cardoso et al. (2006) não encontraram efeito da compactação sobre o volume de raiz do cultivar de soja BR-16 em Latossolo argiloso; entretanto, para o cultivar Embrapa-4 houve $38 \%$ de redução no sistema compactado com Ds de $1,38 \mathrm{~kg} \mathrm{dm}^{-3}$. Esses autores também verificaram maior porcentagem de raízes até $0,05 \mathrm{~m}$ no solo compactado, sendo possível inferir que os cultivares utilizados neste estudo são sensíveis à compactação.

\section{CONCLUSÕES}

O tráfego de máquinas ocasionou a compactação do solo em semeadura direta, com aumento da densidade e resistência do solo à penetração e redução da macroporosidade e porosidade total do solo, sendo a profundidade dessa camada definida pela intensidade do tráfego; a adubação fosfatada não influenciou esses atributos do solo.

A resposta das espécies à forma de adubação fosfatada foi diferenciada, não apresentando influência no crescimento radicular da soja. No milho, quando fornecida a lanço, proporcionou maior área de raízes na camada de 0,00-0,05 m; e quando no sulco, proporcionou menores diferenças no crescimento radicular entre as camadas.

A resistência do solo à penetração de $1,48 \mathrm{e}$ $1,84 \mathrm{MPa}\left(\mathrm{Us}=0,28 \mathrm{~m}^{3} \mathrm{~m}^{-3}\right.$ ) e densidade do solo de 1,32 e $1,35 \mathrm{~kg} \mathrm{dm}^{-3}$ proporcionaram redução de 19 e 27 \% no diâmetro médio das raízes do milho e aumento de 110 e 49 \% no diâmetro das raízes da soja, respectivamente nas camadas de 0,05-0,10 e $0,10-0,20 \mathrm{~m}$.

\section{REFERÊNCIAS}

Barreto AC, Fernandes MF. Produtividade e absorção de fósforo por plantas de milho em função de doses e modos de aplicação de adubo fosfatado em solo de Tabuleiro Costeiro. R Bras Ci Solo. 2002;26:151-6.

Bergamin AC, Vitorino ACT, Franchini JC, Souza CMA, Souza FR. Compactação em um Latossolo Vermelho distroférrico e suas relações com o crescimento radicular do milho. $\mathrm{R}$ Bras Ci Solo. 2010;34:681-91.

Beutler AN, Centurion JF. Efeito do conteúdo de água e da compactação do solo na produção de soja. Pesq Agropec Bras. 2003;38:849-56.

Beutler AN, Centurion JF. Compactação do solo no desenvolvimento radicular e na produtividade da soja. Pesq Agropec Bras. 2004;39:581-8.

Bianchini A, Maia JCS, Magalhaes PSG, Capelli N, Umezu CK. Penetrógrafo eletrônico automático. R Bras Eng Agríc Amb. 2002;6:332-6.

Cardoso EG, Zoratelli L, Piccinin JL, Torres E, Saraiva OF, Guimarães MF. Sistema radicular da soja em função da compactação no sistema de plantio direto. Pesq Agropec Bras. 2006;412:493-501.

Clark LJ, Whalley WR, Barraclough PB. How do roots penetrate strong soil? Plant Soil. 2003;255:93-104.

Crusciol CAC, Mauad M, Alvarez RCFA, Lima EV, Tiritan CS. Doses de P e crescimento radicular de cultivares de arroz de terras altas. Bragantia. 2005;64:643-9.

Empresa Brasileira de Pesquisa Agropecuária - Embrapa. Manual de métodos análises de solo. 2a ed. Rio de Janeiro: Centro Nacional de Pesquisa em Solos; 1997.

Empresa Brasileira de Pesquisa Agropecuária - Embrapa. Sistema brasileiro de classificação de solos. $2^{\text {a }}$ ed. Rio de Janeiro: Empresa Brasileira de Pesquisa Agropecuária; 2006.

Foloni JSS, Lima SL, Bull LT. Crescimento aéreo e radicular da soja e de plantas de cobertura em camadas compactadas do solo. R Bras Ci Solo. 2006;30:49-57.

Freddi OS, Centurion JF, Beutler NA, Aratani RG, Leonel CL. Compactação do solo no crescimento radicular e produtividade da cultura do milho. R Bras Ci Solo. 2007;31:627-36.

Guimarães CM, Stone LF, Moreira JAA. Compactação do solo na cultura do feijoeiro. II: Efeito sobre o desenvolvimento radicular e da parte aérea. R Bras Eng Agríc Amb. 2002;6:213-8.

Jorge LAC; Silva DJC. SAFIRA: Sistema de análise de fibras e raízes. São Carlos: Empresa Brasileira de Pesquisa Agropecuária; 2010.

Leonel CL, Freddi OS, Beutler AN, Centurion PC, Centurion JF. Influência da compactação do solo no crescimento radicular e na produtividade do amendoim. Científica. 2007;35:51-60.

Machado ALT, Reis AV, Ferreira MFP, Machado RLT, Machado ALC, Bauer GB. Influência da pressão de inflação do pneu do trator na resistência do solo à penetração. R Bras Agroci. 2005;11:481-6. 
Malavolta E. Manual de nutrição mineral de plantas. São Paulo: Agronômica Ceres; 2006.

Pagliai M, Marsili A, Servadio P, Vignozzi N, Pellegrini S. Changes in some physical properties of a clay soil in Central Italy following the passage of rubber tracked and wheeled tractors of medium power. Soil Till Res. 2003;73:119-29.

Prado RM, Fernandes FM, Roque CG. Resposta da cultura do milho a modos de aplicação e doses de fósforo em adubação de manutenção. R Bras Ci Solo. 2001;25:83-90.

Santos GA, Dias Júnior MS, Guimarães PTG, Furtini Neto AE. Diferentes graus de compactação e fornecimento de fósforo influenciando no crescimento de plantas de milho (Zea mays) cultivadas em solos distintos. Ci Agrotec. 2005;29:740-52.
Santos RD, Gatiboni LC, Kaminski J. Fatores que afetam a disponibilidade de fósforo e o manejo da adubação fosfatada em solos sob plantio direto. Ci Rural. 2008;38:576-86.

Secco D, Reinert DJ, Reichert JM, Silva VR. Atributos físicos e rendimento de grãos de trigo, soja e milho em dois Latossolos compactados e escarificados. Ci Rural. 2009;39:58-64.

Torres E, Saraiva OF. Camadas de impedimento do solo em sistemas agrícolas com soja. Londrina: Empresa Brasileira de Pesquisa Agropecuária; 1999. (Circular técnica, 23)

Valicheski RR, Grossklaus F, Sturner SLK, Tramontin AL, Baade ESA. Desenvolvimento de plantas de cobertura e produtividade da soja conforme atributos físicos em solo compactado. $\mathrm{R}$ Bras Eng Agríc Amb. 2012;16:969-77. 